\title{
微小形状特徴に基づく類似のテクスチャ画像群の合成手法 *
}

\author{
田村仁** 阿刀田央一*** 本多 庸 悟 $^{\dagger}$
}

A Synthesis Method for Similar Texture Images based on Minute Shape Features

Hitoshi TAMURA, Oichi ATODA and Tsunenori HONDA

\begin{abstract}
A synthetic method for generating arbitrary number of not the same but similar texture images has been developed. The method includes processes to extract basic shape elements from texture images originating in actual objects, to select them to reappear the image features and to arrange them in an image plane. The authors have already proposed the shape-pass type filter bank assuming that the sensual impression mainly depends on minute shapes existing in the texture images. By use of nine basic shape elements, namely black/white-roof, black/white-line, black/white-snake, black/white-pepper, and cliff, natural texture images originating in actual objects have been characterized by feature vectors in a nine dimensional space. To generate arbitrary number of similar texture images, minute shape pieces are collected from original texture images and arranged so that the feature vectors may become locally similar to the original images. By the method, a number of similar texture images have successfully been generated, and the results of questionnaires on the synthesized texture images to universities students have shown the effectiveness of the method.
\end{abstract}

Key words: texture synthesis, shape-pass filter, shapes of texture elements, pictorial feature of textures, impressions of textures

\section{1. 序}

本研究では，実際の形状に由来するテクスチャ画像から基本形状 要素たけを抽出し，それらを自在に組み合わせることで, 互いに類 似するが同一ではない新たなテクスチャを好きな数だけ合成する 手法を提案する.

テクスチャを識別するための様々な手法が提案されてきている 12)3). しかし，テクスチャ画像に対して人間が受ける「ざらざら」 感などの印象は，従来のそれそれれ手法では，完全に説明できない と思われる.著者らは，この要因をテクスチャに存在する微小な形 状によると仮定し，「形状通過型」フィルタバンクを提案した 4). これは，角状，線状，溝状などの5種類の微小形状と，明暗対称な 段状を除く 4 種類を明暗反転した形状の，合計 9 種類の基本形状 要素を対象とする．これによると，実際の対象物に由来する「自然 なテクスチャ」を多数のクラスタに分類でき，9種類の形状基本要 素それそれがテクスチャ判別に有効であることが文献 4)の実験に よって確かめられている.

互いに類似するが,同一ではないテクスチャ画像を好きな数だけ 合成するために,ここでは様々なテクスチャ画像から抽出された微 小形状要素を含む要素片を収集し，特幑べクトルが原画像と局所的 にも類似するように選択して配置することを考える.同様の画像を 好きな数だけ合成するには, 同じ微小形状要素片を, 同じ強さで同 じ密度を保ちながら，異なる配置にすればよい，

本論文では, 実際のテクスチャ画像について同一でない類似のテ クスチャ画像を，提案する手法により多数生成する実験を行い，ア ンケート調查により，その妥当性を確認する.

$\begin{array}{cl}* & \text { 原稿受付 } \text { 平成 } 13 \text { 年 } 6 \text { 月 } 19 \text { 日 } \\ * * & \text { 正 会 員 東京理科大学経営学部 (久喜市下清久 } 500 \text { ) } \\ * * * & \text { 正会 貝 東京農工大学大学院 (小金井市中町 2-24-16) } \\ \dagger & \text { 正 会 員 東京工大学工学部 (小金井市中町 2-24-16) }\end{array}$

\section{2. 形状通過型フィルタ}

Fig.1 に本手法が取り扱うテクスチャ基本形状要素を示す. 基本 形状要素は，角張った形状の「黒かど(roof)」，細長い形状の「黒 せん(line)」，曲がりくねった形状の「黒みぞ(snake)」，粒状の「 黒つぶ(pepper)」，明度の段を示す「だん(cliff)」と，明暗反転し た形状の「白かと」「白せん」「白みぞ」「白つぶ」である.形状 通過型フィルタは,従来の画像用線形フィルタのポイントスプレッ ド領域に相当するフィル夕領域を設定し，そこに含まれる画素を用 いた非線形処理により,フィルタ領域の中心画素に対する出力を得 るものである.この領域の大きさは任意であるが, 微小な形状要素 を捉えられるサイスでなければならない，後述する実験では，11 $\times 11$ 画素と設定した。

フィルタ内部では, 基本形状要素をパターンとしてではなく，定 義された手続きによって抽出する. Fig.2のような「つぶ」フィル 夕を例としてフィルタ領域内の動作を説明すると次のようである.

1）フィルタ領域内の平均明度を用いて領域内の画素を 2 值化し, 中心画素から塗りつぶし処理を行う.

2) 塗りつぶされた領域が，フィル夕領域の外周に達しな ければ，中心につぶが存在すると定義する.

3）つぶがあた場合，つぶがはっきりしているか，淕り つぶされた領域の境界部分における平均明度差を計算し，それを 「特幑の強さ」として出力する.

一つの形状通過型フィルタの出力画像から,その画像の二乗平均 振幅值,

$r=\sqrt{\frac{\sum_{X Y} y^{2}}{X Y}}$

( $\mathrm{y}$ は画素の明度, $\mathrm{X}$ と $\mathrm{Y}$ は画像の大きさ)

をフィルタ出力の代表値とする.これを 9 種類のフィルタ全てにつ

いて行い, それら代表值から9次元の特徵ベクトルを得る。 

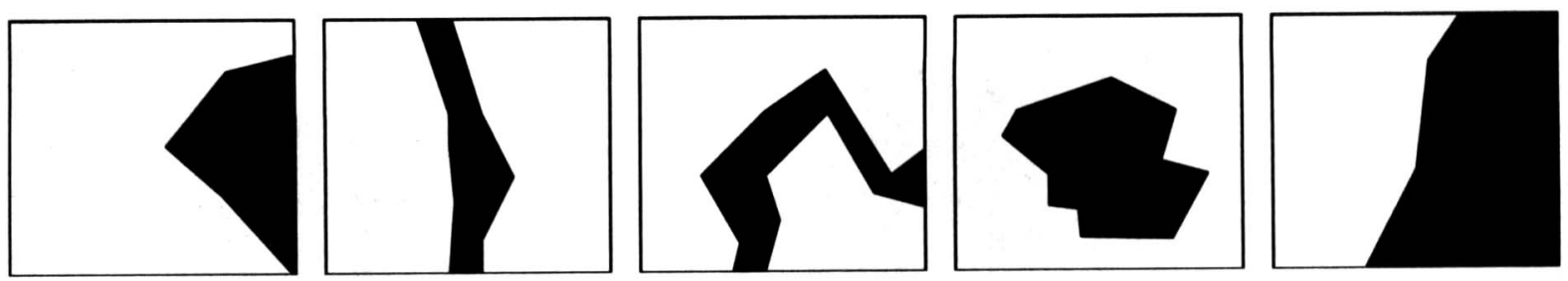

Fig.1 Shape bases of textures (black-roof, black-line, black-snake, black-pepper, cliff)

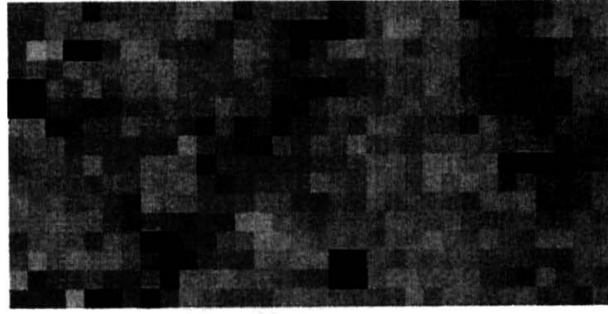

(A) Input image

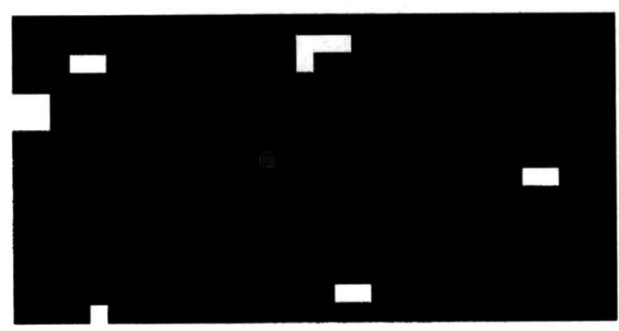

(B) Output image

Fig.2 An example of black-pepper filter outputs

\section{3. テクスチャ合成}

形状通過型フィル夕は, 局所的なフィル夕領域内の情報だけを利 用するものであるが, 画像全体として「ざらざら」感のような大局 的な特徴を再現するテクスチャを合成するためには,生成する画像 上で形状特徴の配置を考虑する必要がある. そこで本研究では, 特 定の自然な実際的な対象物に由来するテクスチャを対象に, それと 同じ形状特徴を，同程度の強さと密度を示すように配置する.

以後, 基になるテクスチャの原画像のことを対象画像, 合成され た画像を合成画像と表記する.

\section{1 形状要素片の収集}

合成画像中に配置する形状要素を「形状要素片」と呼ぶ.この形 状要素片は, 形状通過型フィルタのフィル夕領域よりも小さくでき ない. 形状要素片は, 形状要素を複数含むものや, 特徵の強弱を示 すものなど多数を用意する必要がある.これらを, より自然なテク スチャの合成のため, 十分な数のサンプル画像から抽出する.

サンプル画像にフィルタバンクを適用し, 9 枚の出力画像を用意 する. テクスチャ画像と 9 つの出力画像を, $11 \times 11$ 画素の格子状 に分割する. 分割されたサンプル画像の一つの格子部分を, 一つの 形状要素片とする. 格子の大きさは, 形状通過型フィルタのフィル 夕領域の大きさに等しい.

それぞれの出力画像上で, 各形状要素片に対応する格子部分の二 乗平均振幅值 $\mathbf{r}$ を計算し, 形状要素片に対する特徵ベクトルとす る. 更に特徴ベクトルの各次元を 2 值化して $2^{9}$ 通りの組合せ, 例 えば「かど, みぞが顕著」のような種別に分類し, 形状要素片とそ の特徵ベクトルの記録をとる.この組合せのことを特徵パターンと
呼ぶことにする．

形状要素片を無䭾に収集しないよう, 収集する上限の数を決めて おいた.ここでは計算機による処理時間を考慮し, 特徵パターンこ とに 1024 個の形状要素片を収集することにした。

\section{2 合成画像の背是生成}

自然なテクスチャの中には,形状特徵がまばらに存在するものも あるため, 隙間を埋める背景画像が必要となる.この背景画像とし ては形状特幑をほとんど含まない,対象画像とよく似た周波数成分 を持つ画像を用意する.これには文献 4)により作成したガウス性 雑音画像を用いる.これは, 対象画像とよく似たパワースペクトル の包絡線を与えた, ランタムな空間周波数成分を逆 FFTして得る.

\section{3 形状特证の目己圈}

次に, 背景画像に対して, 適切な形状要素片の画素を置き, 形状 特徵を配置する. 対象画像の 9 枚の出力画像を同時に走査し, ある 画素位置での特徵ベクトルが 0 以外を示した場合, 同じ特徵パター ンに分類されたものの中から, 最も特徵空間上でのユークリッド距 離が近いものを選択し, 合成画像上の同じ位置に形状要素片の中央 画素が重なるように配置する. 配置するとは, 具体的に, 形状要素 片の画素で, 背景画像の画素を置き換えることをいう.

形状要素選択時に同じ特徵パターンの形状要素が存在しない場 合は, 目標とする特徵べクトルの中で, 小さい值を示す次元から順 にマスクして, 近傍の特徴パターンの中から選択を行う.

一つの画素の特徵点に対し, 広がりのある形状特幑片を対応させ ることでニつの影響が生じる. 一つは形状要素片の配置によって， 意図しない別の形状を生成する可能性があること, もう一つは, 近 傍に別の特徵点が存在した場合, 形状要素片の重ね合わせでは, 同 時に複数の形状要素を再現できないことである.

前者は, $11 \times 11$ 画素の正方形という便宜上設定された形状要素 片の形自体がかど」になるなど, 外周部分と背景部分の相互作用 によって境界部分に新たな形状が生成される.しかし, 形状要素片 が背景に馴染むように境界部分をぼかすことで,仮に新たな形状が 生成されても弱い出力に留めることができる.ぼかし方としては, 形状要素片の外周部と, その周辺領域の画素で, 加重平均をとれば よい.

また, 後者に対処するために, 新たに形状要素片を置こうとする 領域内に別の特徴点がある場合, それも含めて再現する.このため, 対象画像内のその領域の二乗平均振幅值を計算し, それと一番近い 特徵ベクトルを持つ形状要素片を選択させる. その上で, 形状要素 片を重ねることを禁止する。

\section{4 被数の画像合成}

ある対象画像と類似の微小形状特徵を示す合成画像を，好きなだ け複数生成するためには,特徵の配置を変更すればよい.すなわち, 対象画像と同じ微小形状を, 同じ強さで同じ密度を保ちながら, ラ ンダムに配置する.

具体的な手順として, 対象画像に形状通過型フィルタバンクを適 
Original image

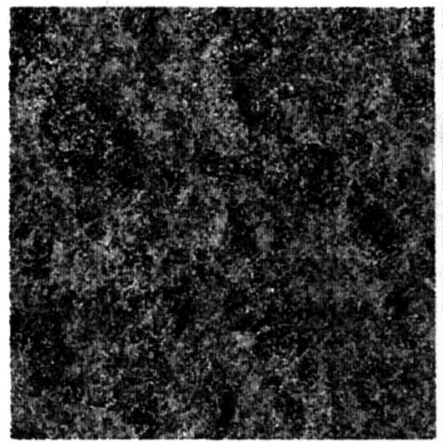

Synthetic image (1)

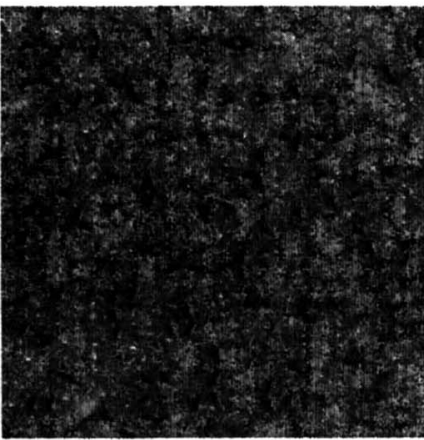

Synthetic image(2)

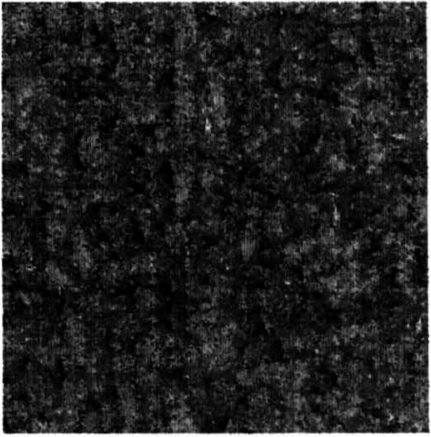

Synthetic image(3)

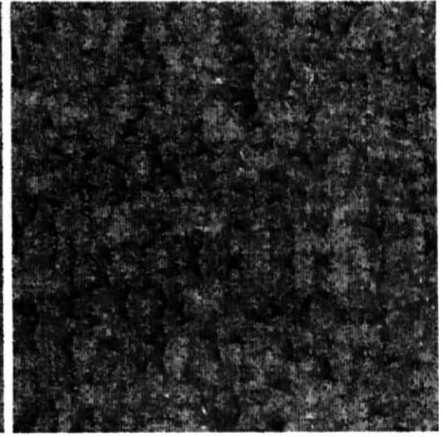

(a) An example of synthesized texture with similar feature vector as the original image (inner product $=0.95$ )
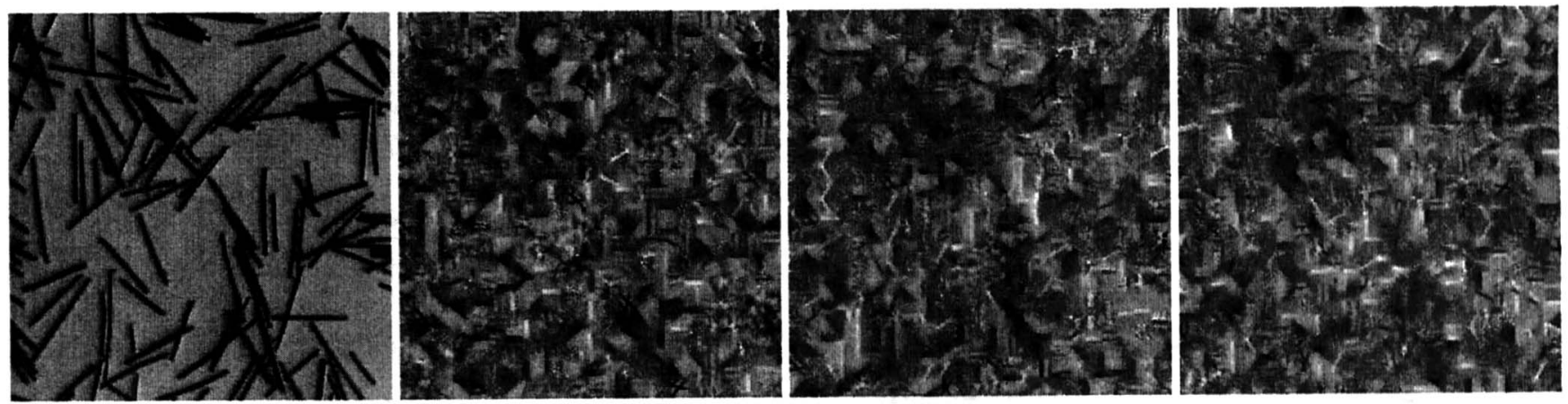

(b) Another example of synthesized texture with similar feature vector as the original image (inner product $=0.94$ )
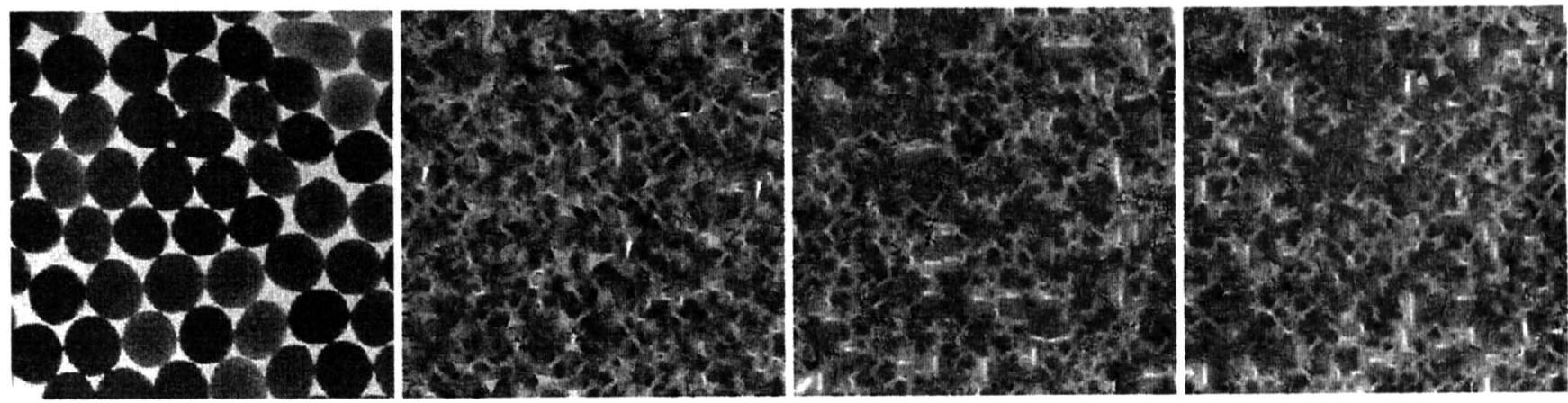

(c) An example of synthesized texture with different feature vector from the original image(inner product=0.74)

Fig.3 Examples of original images and synthesized textures

(inner product of original image's feature vector and synthesized texture's one)

用し，9 枚の出力画像を得た後，9枚それぞれを $11 \times 11$ 画素の西 方格子状に分割し，この格子の組を，ランダムに並べ替える.この 特徵点の配置が異なる 9 枚の出力画像を元に, 別の合成画像を生成 する.

なお, 配置の異なる出力画像を張り合わせ, あるいは切り取って 任意サイズの出力画像を作ることで, 任意サイズのテクスチャを合 成することも可能となる.

\section{4. 合成およひ評価の実験}

\section{1 合成画像の生成実験}

実験用の写真素材 6) と, 著者らが撮影した写真から, 316 枚の一 様な自然なテクスチャ画像を選択した．これを原画像に，文献 4) に示した方法で, 最も形状特徴が存在しそうな分解能に正規化し, $256 \times 256$ 画素を切り出し, 灰色度 256 階調, 明度平均 128 , 標準
偏差 32 に標準化したものを実験に用いる.

それら画像を無作為に各 158 枚の A 群と B 群に分割する. A 群 から形状要素片を収集し, それを用いて B 群の各画像を対象とし て，3.4に示した方法を用いて, 各 4 枚ずつ, 計 632 枚のテクスチ ヤ画像を実際に合成した.

出力結果の例を Fig.3 に示す.

\section{2 再現性の数? 目的評価}

合成画像が, 対象画像の形状特徵を再現しているかどうか確認す るため, 改めて合成画像に形状通過型フィルタバンクを適用し, 両 者の特徵ベクトルを比較してみた. 両者を単位ベクトルにし, 内積 をとる. 全 632 合成画像に対し, その分布を Table 1 に示す. 内 積が 0.8 を超え, 対象画像とほぼ同じ方向を示すと思われるものが $72.6 \%$ 存在し, 全体としては形状特徵をよく再現できたことを示 す. 
Table 1 Frequency distribution of normalized inner products of" target and synthetic featured vectors

\begin{tabular}{cr|r|c}
\hline \multicolumn{2}{c|}{$\leqq$ Range $<$} & Freq. & Cumulative(\%) \\
\hline 0.9 & 1.0 & 161 & 25.5 \\
0.8 & 0.9 & 298 & 72.6 \\
0.7 & 0.8 & 150 & 96.4 \\
0.6 & 0.7 & 18 & 99.2 \\
0.5 & 0.6 & 5 & 100 \\
0.4 & 0.5 & 0 & 100 \\
0.3 & 0.4 & 0 & 100 \\
0.2 & 0.3 & 0 & 100 \\
0.1 & 0.2 & 0 & 100 \\
0.0 & 0.1 & 0 & 100 \\
\hline
\end{tabular}

Fig.3の合成例において,(a)および(b)は特徵べクトルに関して比 較的良く特幑が再現できた例である。(b)は微小ではなく大きく長 い形状要素を含むため, 視覚的印象は異なるものとなっている. (c) は数量的に特徵を再現できなかった例で,微小な形状要素よりも大 きなサイスの構造の存在のためである.

\section{3 アンケートによる評価}

本手法によって合成されたテクスチャ画像が,視覚的に似ている かどうか客観的に確かめるため，大学生 31 人にアンケート調查を 行った.アンケートは, 図 3 に示した synthetic image(1) と synthetic image(2)のような 2 枚の合成画像を一組にして，A4 紙 一枚に印刷したものを 1 問として，計 8 問用意した。

同一の対象画像からの合成画像の中から 5 組の組合せを用意し， Q1〜Q3，Q5 およびQ6 とした.また，被験者がきちんと回答して いるかどうか確認するために，全く同じ合成画像の組合せを Q4， 逆に, 異なる対象画像からの合成画像の組合せ 2 組を Q7 と $\mathrm{Q} 8$ と した.アンケートは「2枚の画像の感じは，お互いに，(1)非常によ く似ている, (2)まあ, 似ている, (3)あまり似ていない, (4)まったく 似ていない」の 4 段階の回答項目とした。

その結果を Table 2 に示す. Q4, Q7 およびQ8 の結果から，回 答の信頼性を確認できる. 残る 5 問に対しては，55〜65\%が似て いると回答している。これにより次のことがいえる。

（1）同一対象画像からの 2 枚の合成画像は, 過半数が似てい ると判断していた．たたし，似ていないとの回答も無視 できない.この 5 問に対する個人別の回答を確認すると， それそれ判断が散らばっており，極端に偏った判断をし た人は少数であった。

（2）どの点に着目して判断したかについては，被験者の一人 が，印刷時に生じた全体的な濃淡に影響されて，まった く同一の画像に対して「あまり似ていない」と回答した ように，わずかな差異に影響を受けている．画像を大き く印刷したことの影響も考えられる。このように，極め てわずかな印象の違いでもあれば，似ていないと回答さ れる傾向があると考えられる。

これらを考虑すれば,過半数の被験者が似ているとした同一対象 画像からの 2 つの合成画像は,視覚的に似ているとしてよいと判断 される.

\section{4 対象画像自体から要案片を収集した場合の合成例}

4.1 の実験では, サンプル画像を A 群 B 群に分け, 対象画像とは 異なる画像から抽出した形状要素片を用いて合成を行った。これ
Table 2 Result of a questionnaire examining whether two synthetic images from same original image look like each other

\begin{tabular}{l|r|r}
\hline Questionnaires & Number of (1)and(2) & $\%$ \\
\hline Q1 Original image is the same & 18 & 58.1 \\
Q2 Original image is the same & 17 & 54.8 \\
Q3 Original image is the same & 20 & 64.5 \\
Q4 Quite the same images & 28 & 90.3 \\
Q5 Original image is the same & 19 & 61.3 \\
Q6 Original image is the same & 20 & 64.5 \\
Q7 Original image is different & 0 & 0.0 \\
Q8 Original iamge is different & 0 & 0.0 \\
\hline
\end{tabular}

は, 着目していた微小な形状要素以外にも, 対象画像が有するなん らかのテクスチャの特徵が形状要素片に混入する影響を考虑した ためである。

逆に，対象画像自体から形状要素片を抽出し，画像を再合成する 場合，なんらかのテクスチャ特徵を受け継き，より印象が似ること も考えられる.そこで実際に，对象画像自体から形状要素片を抽出 し，それだけでテクスチャ合成を行った結果を Fig.4に示す.Fig.4 の(a)から(f)において左側は原画像，右側が合成画像である。この うち(a)から(c)に示した画像は，Fig.3に示したものと対応する.

(b)と(c)では，それそれの形状要素片に背景の白が含まれ，結果 としてそれを合成したときに，全体の背景が白く抜けて見える感じ が再現でき，より印象が似て見える.局所的な特徵だけでなくここ のような大域的な特徴も人間の視覚に対して強く影響することが 示されている。

(d)や(e)では葉先の細かい形状が再現された。これらの特徵は， 3.の実験の場合では再現できなかったものである. 微小な形状特徵 を，大きく9つに類別したことにより，3.の実験の合成時には，人 間の視賞上ては微妙に異なる印象を与える特徽をもった形状要素 片によって代用されてしまったことによるものと考えられる。

これは, 基本形状要素の数が不足，あるいは使用した形状要素片 の大きさに問題があるといえる.ただし，形式的に微細な違いにこ だわり, 形状基本要素の数を増やすことを考えても，その数を爆発 させるだけで無意味である.人間の視覚に強く影響を与える基本形 状要素とそのサイスを探しだすことが今後の課題となる.

\section{5. 結睔}

本論文では, 形状通過型フィルタバンクを利用して，微小形状要 素を自在に組み合わせるテクスチャ合成手法を提案した。実際に 158 枚の自然なテクスチャの形状特徵を再現する実験を行い, 次の 結果を得た。

（1）特徴ベクトルに関して，72\%超のテクスチャの形状特徴 を再現できた，再現できなかったものは，強い形状特徵 を稠密に含むもの，あるいは微小な形状要素より大きな 構造を含むテクスチャである.

（2）同じ対象画像について複数の合成画像を生成し，アンケ 一トによって視覚的に似ているかどうか確認したとこ ろ，過半数が似ていると判断した。これにより，複数の 類似したテクスチャ画像を生成できることが示された。

なお，本研究における実験では，形状通過型フィルタバンクで使 用したフィル夕領域の大きさと, 形状要素片の大きさが共に $11 \times$ 


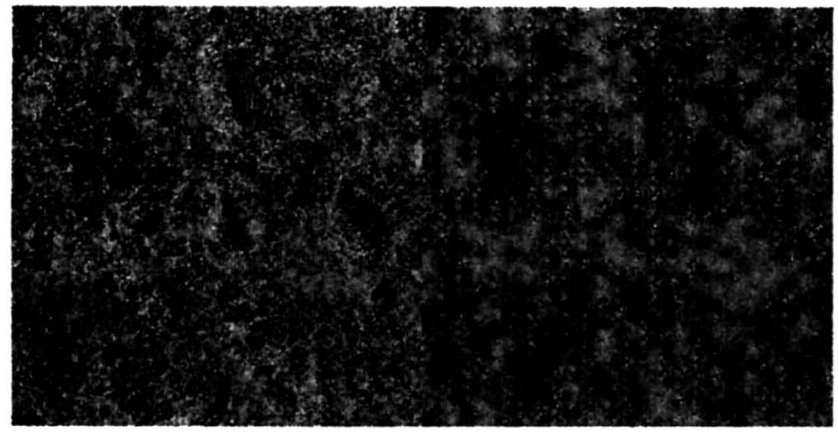

(a) Sample A

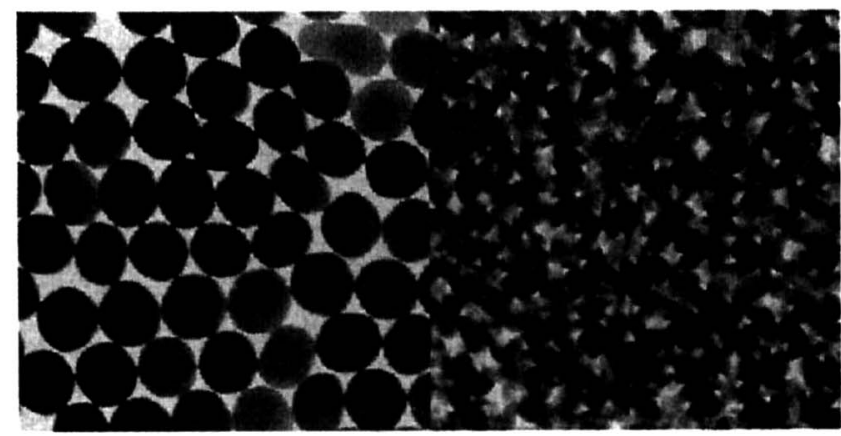

(c) Sample C

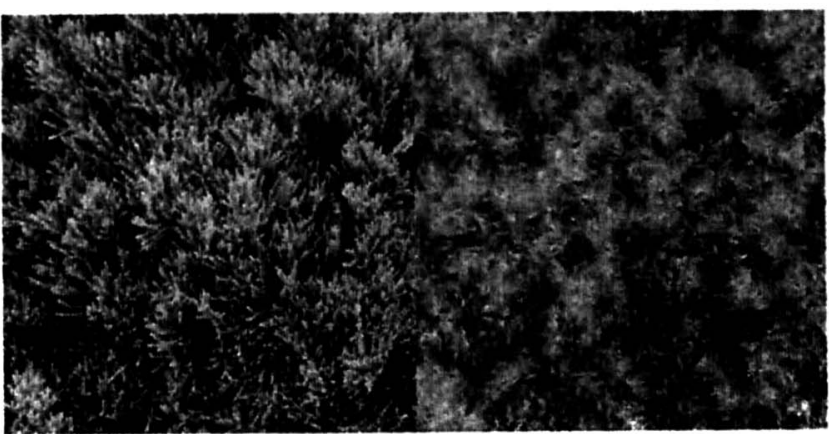

(e) Sample E

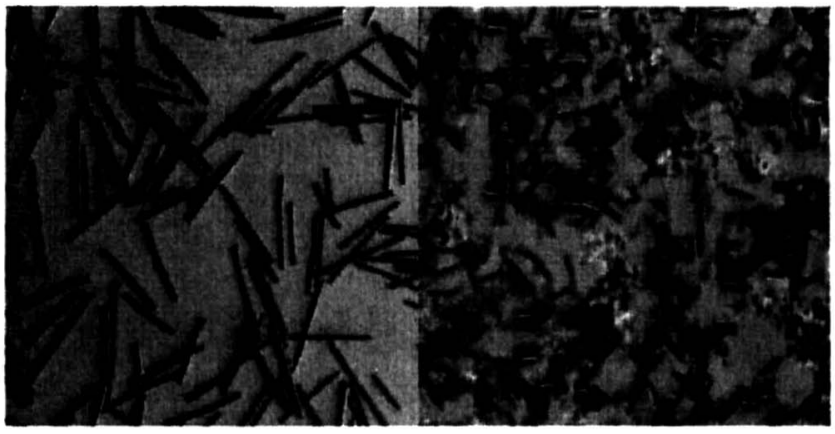

(b) Sample B

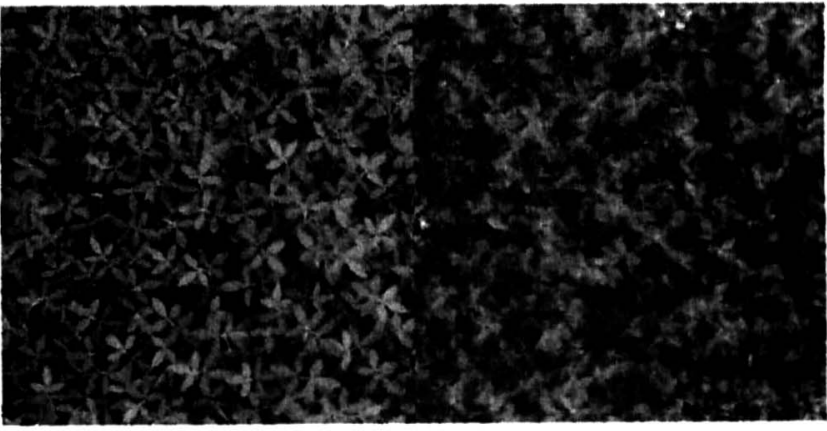

(d) Sample D

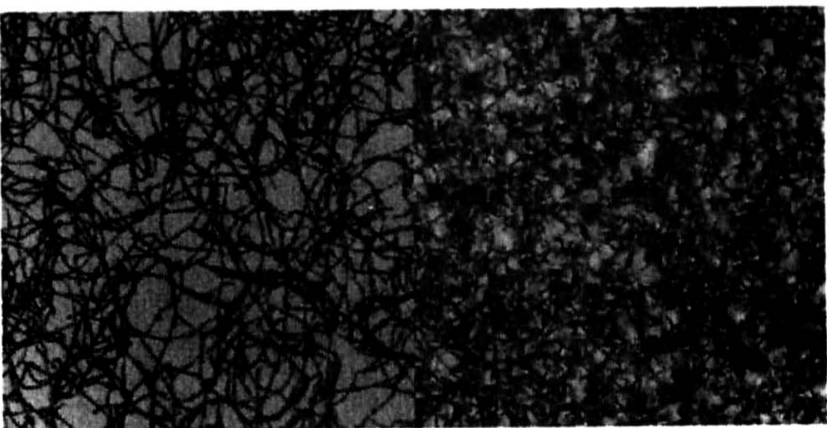

(f) Sample F

Fig.4 Examples of original images and synthesized textures using minute shape elements extracted from their own original images

11 画素の正方格子としたが, 対象画像の性質, 解像度等に適合す るように，この正方格子の大きさを調整することが考えられる.

また, 今後の課題として,この手法による計画的に形状要素を組 み込んだ画像を使い,個々の形状特徵が視覚に与える影響の数量化 を図ること, また, 個々の対象画像を特徵付けるような局所的な特 徵の存在をさらに検討することが挙げられる.

\section{考文献}

1) R.M. Haralick: Statistical and structural approachis to textures, IEEE Proc. No.67, pp.786-804, 1979.

2) 出口光一郎, 森下䉷: テキスチャーの解析手法, 計測と制 御, vol.16, no.2, pp.184-194, 1977.

3) E. Salari and $Z$. Ling: Texture segmentation using hierarchical wavelet decomposition, Pattern Recognition, vol.28, no.12, pp.1819-1824, 1995
4) 田村仁, 阿刀田央一: 自然なテクスチャの特徵抽出用「形状通過型」非線形 フィルタバンク, 電子情報通信学会論文誌(D-II), vol.J82-D-II, No.12, pp. 2260-2270, 1999.

5）田村仁: 非線形フィルタバンクによるテクスチャ画像のクラスタリンク，情 処学会研究報告, CVIM Vol.97,No.10,pp.91-98, 1997.

6）テータクラフト(編): 素材辞典 vol1,2,3,8,9,15,19, テータクラフト, 札幌 1994 1996.

7) 田村仁, 阿刀田央一: 非線形フィルタバンクによるテクスチャ画像からの特 徵抽出と触感の対応," 第 3 回画像センシングシンボジウム講演論文集 (SII'97), pp.195-200, 1997.

8) H.TAMURA, O.ATODA: A Nonlinear Filter Bank for Shape-Based Texture Analysis, Proceedings of the 3rd Asia-Pacific Conference on Control and Measurement (AP CCM'98), pp.58-62, 1998.. 